\title{
CANCER
}

\section{Influence of clinical factors, diet, and drugs on the human upper gastrointestinal glutathione system}

\author{
H Hoensch, I Morgenstern, G Petereit, M Siepmann, W H M Peters, H M J Roelofs, \\ W Kirch
}

See end of article for authors' affiliations

.....................

Correspondence to: Professor H Hoensch, Department of

Gastroenterology, General Hospital of Gross-Gerau, Wilhelm-Seipp-Strasse 3, D-64521 Gross-Gerau, Germany; H.P.Hoensch@ vff.uni-frankfurt.de

Accepted for publication 14 May 2001

\begin{abstract}
Background: Glutathione (GSH) and the cytosolic glutathione S-transferases (GSTs) protect the gastrointestinal mucosa against the toxic effects of a wide variety of compounds, such as reactive oxygen species and electrophiles.

Aims: We wished to investigate the distribution along the upper gastrointestinal mucosa and the influence of clinical variables on components of the GSH system to learn more about factors which control its cytoprotective properties.

Methods: Antral and duodenal biopsies of normal appearing mucosa were collected from 202 patients (104 males, 98 females; mean age 62 years) undergoing upper gastrointestinal endoscopy. GSH content was examined by high pressure liquid chromatography, GST enzyme activity by 1-chloro-, 2, 4-dinitrobenzene conjugation, and levels of the GST classes alpha, pi, and theta by western blot.

Results: GSH, GST enzyme activity, and GST alpha levels were significantly lower $(p<0.001)$ in the antrum than in the duodenum (antrum $v$ duodenum: GSH 23.0 (0.7) v 35.0 (1.0) nmol/mg protein; GST activity 626 (19) v 832 (22) nmol/mg protein/min; GST alpha 4.5 (0.5) v 20.0 (0.7) rg/mg protein) while GST pi content was significantly higher $(p<0.001)$ in antral than in duodenal biopsies (16.5 (0.7) $\vee 11.2(0.5) \mathrm{\mu g} / \mathrm{mg}$ protein). Antral GSH and GST activities were markedly lower in males compared with females $(p<0.01)$. Some drugs (cisapride, diuretics, cortisol, analgesics) increased GST pi and GST alpha content but cytostatic drugs suppressed duodenal GST activity. High intake (>3 days a week) of vegetables enhanced duodenal GST alpha and GST pi and high intake of fruits the antral content of GST theta 1 .

Conclusions: The gastrointestinal GSH system represents the antitoxic barrier of the mucosa; its activity is influenced by localisation, sex, and drugs, and its enzymes are stimulated by a high intake of vegetables and fruits.
\end{abstract}

$\mathrm{T}$ he conjugation reaction with the sulphhydryl group of glutathione (GSH; $\gamma$-glutamyl-cysteinylglycine) plays an important role in protecting cellular proteins and nucleic acids from toxic substances. ${ }^{1}$ GSH conjugation in humans is catalysed by two supergene families containing eight classes with 16 different soluble glutathione S-transferase (GST) subunits and six membrane associated proteins, described in detail by Hayes and Strange ${ }^{2}$ (GST; EC 2.5.1.18). These enzymes represent the first step in the synthesis of mercapturic acids, an important group of excretion products. Metabolism of foreign compounds usually involves two distinct stages referred to as phases I and II: the former is characterised by initial oxidation of the xenobiotic, mostly by cytochrome P450 (CYP) monooxygenases, ${ }^{3-5}$ while the latter consists of conjugation reactions between the metabolite and an endogenous substrate catalysed by GSTs, UDP-glucuronosyl transferases, sulphotransferases, etc, or reduction reactions mediated by epoxide hydrolase and quinone reductase. ${ }^{1}$

Since the first description of GST isoenzymes in humans by Kamisaka and colleagues, ${ }^{6} 22$ have been identified. ${ }^{12}$ Human cytosolic GSTs are found as homo or heterodimers (soluble proteins), and are classified according to structural similarities into eight classes: alpha, pi, mu, theta, kappa, sigma, zeta, and omega. ${ }^{5}$ Class alpha enzymes are basic proteins with intermediate subunit molecular masses, class mu enzymes are neutral proteins with high molecular masses, whereas class pi GSTs are acidic proteins of low molecular mass. ${ }^{5}$ Meyer et al reported the first purification of GSTT1-1 from human liver, and it has been proposed that the class theta enzymes are possibly more ancestral in origin than classes alpha, mu, and pi. ${ }^{4}$ GST alphal (GSTA1), GST alpha2 (GSTA2), GST mul (GSTMl), GST pil (GSTPl), GST thetal (GSTTl), and GST theta2 (GSTT2) appear to be the most abundant soluble transferases in humans.

Expression of the multiple isoforms of GSTs is tissue specific and may differ among individuals, thereby leading to variations in detoxification capacity. ${ }^{4}$ For instance, class alpha enzymes are abundant in the liver, small intestine, kidney, and adrenals $^{6-15}$ while class pi enzymes are widely distributed in extrahepatic tissues including the placenta, kidney, oesophagus, stomach, small and large intestines, breast, lung, erythrocytes, thyroid, and uterus..$^{10-12}{ }^{16}{ }^{17} \mathrm{In}$ contrast, the presence of class mu does not appear to be organ specific; due to a genetic polymorphism, only about $55 \%$ of Caucasian individuals express class mu GST. ${ }^{18}$ It is known that apart from class mu, classes alpha, pi, theta, and zeta GST are also polymorphic in humans. ${ }^{2}$ Class theta cytosolic GST has been found in human liver. $^{7}$

There is mounting evidence for a role of GSTs in drug resistance in cancer chemotherapy with the enzyme classes pi and alpha appearing to be of particular pathophysiological importance. Increased expression of GST pi enzymes in gastric carcinomas, but also in colon, cervical, and bladder tumours, compared with levels in adjacent normal tissues, may offer a

Abbreviations: GSH, glutathione; GST, glutathione S-transferase; GSTA, GST alpha; GSTP, GST pi; GSTT, GST theta; NSAIDs, non-steroidal anti-inflammatory drugs; PBS, phosphate buffered saline 
Table 1 Patient characteristics and endoscopic findings

\begin{tabular}{lcc}
\hline Characteristics & Males $(\mathrm{n}=104)$ & Females $(\mathrm{n}=98)$ \\
\hline Age $(\mathrm{y})$ & $57.5(1.9)[16-92]$ & $65.9(1.8)[18-92]$ \\
Height $(\mathrm{cm})$ & $172.9(0.8)[150-200]$ & $162.3(0.8)[145-186]$ \\
Body weight $(\mathrm{kg})$ & $75.2(1.3)[50-112]$ & $67.2(1.8)[38-150]$ \\
BMl $\left(\mathrm{kg} / \mathrm{m}^{2}\right)$ & $25.1(0.4)[13.75-36.99]$ & $25.4(0.6)[12.77-57.16]$ \\
Endoscopic diagnosis (n) & 18 & 16 \\
$\quad$ Normal & 10 & 20 \\
Erythematous gastritis only & 25 & 13 \\
$\quad$ Gastrointestinal erosions & 30 & 23 \\
Gastrointestinal ulcers & 21 & 26 \\
$\quad$ Other conditions & \\
\hline Values are mean (SEM) [range]. & & \\
BMl, body mass index. & & \\
\end{tabular}

selective advantage to tumour cells. ${ }^{10}{ }^{19-23}$ Increased expression of classes alpha and mu GSTs have also been detected in refractory tumours and drug resistant cell lines. ${ }^{1124-26}$

However, data on the distribution of GSH, GST activity, and classes alpha and mu along the upper gastrointestinal tract are limited, partially due to the relatively small number of studies previously conducted and their modest sample sizes. Therefore, we investigated the distribution and individual variations in the components of the intestinal glutathione system (GSH, GST activity, GSTA, GSTP, and GSTT1 and GSTT2) in the antral and duodenal mucosa of a large patient population. We also collected clinical data from individual patients and these variables were related to the parameters of the GSH system.

\section{METHODS}

\section{Patients, biopsies, and tissue preparation}

Two to three biopsies of both the antral and duodenal mucosa were obtained from 202 patients ( 104 males and 98 females; age range 16-92 years; mean age 62 (1) years) undergoing routine upper gastrointestinal endoscopy at the General Hospital of Gross Gerau, Germany. Biopsy specimens were taken from mucosal tissue of normal appearance using standard fibreglass video endoscopes from either Pentax (Video Pentax EG 290 P; Pentax GmbH, Hamburg, Germany) or Olympus (Olympus XQ 20; Olympus GmbH, Hamburg, Germany). Biopsy tissue was washed in ice cold $0.9 \% \mathrm{NaCl}$, quickly frozen in liquid nitrogen, and stored at $-80^{\circ} \mathrm{C}$ until further use. Immediately after endoscopy, a standardised form was completed for each patient which contained information on age, sex, diagnosis, drug therapy, family history, laboratory parameters, and endoscopic findings, including a food frequency questionnaire. Vegetables (cucumber, cabbage, broccoli, asparagus, spinach, peppers, beans, peas, cauliflower, brussels sprouts) and green salad were consumed either 1-3 days a week (low intake) or 4-7 days a week (high intake).

Fruit intake (apples, bananas, grapes, pears, berries, pine apples, plums, cherries) was considered low ( 1-3 days a week) or high (4-7 days a week). Potatoes, onions, garlic, spices, rice, and bread were examined separately. All information was collected prospectively by interview of the patient and using clinical data charts. Patient demographics are summarised in table 1. All patients provided written informed consent. The protocol for the study was approved by the ethics committee of the University of Dresden, Germany.

All biopsies were transported on dry ice within 12 hours. Just before use, biopsies (about $30 \mathrm{mg}$ ) were rapidly thawed and homogenised on ice in five volumes of homogenising buffer (250 mM sucrose, $20 \mathrm{mM}$ Tris $\mathrm{HCl}, 1 \mathrm{mM}$ dithiothreitol, $\mathrm{pH}$ 7.4) using small plastic tissue grinders. The homogenates were centrifuged at $150000 \mathrm{~g}$ for 50 minutes at $4^{\circ} \mathrm{C}$. The supernatant was frozen in liquid nitrogen and stored at $-20^{\circ} \mathrm{C}$ in small aliquots until analysis. Part of the supernatant was also diluted with $10 \%$ trichloroacetic acid for use in determining GSH content.

\section{Biochemical assays}

Biochemical analysis of the specimens was performed at the University Hospital St Radboud, Nijmegen, the Netherlands. Protein content was assayed in duplicate using the method of Lowry et al with bovine serum albumin as standard. ${ }^{27}$ GST enzyme activity with 1-chloro-2,4-dinitrobenzene as substrate was determined at $25^{\circ} \mathrm{C}$ according to Habig and colleagues. ${ }^{28}$ Total GSH was quantified by high performance liquid chromatography after reaction with monobromobimane using a modification of the method of Fahey and Newton..$^{29} 30$

GSTA (containing GSTAl and GSTA2) and GSTP levels were determined using ELISAs, as recently described. ${ }^{31}{ }^{32}$ Briefly, polystyrene 96 well microtitre plates (Greiner, Alphen a/d Rijn, the Netherlands) were incubated with $100 \mu \mathrm{l}$ of phosphate buffered saline (PBS) containing GSTA or GSTP monoclonal antibodies, as developed by Peters and colleagues. ${ }^{19} 33$ After coating for 12 hours at $4^{\circ} \mathrm{C}$, unfixed antibodies were removed, and the plates were incubated at room temperature with PBSTween containing $1 \%$ bovine serum albumin to block non-specific binding. One hour later, the plates were washed three times with wash buffer (PBS containing 0.05\% Tween 20 ) and incubated for 12 hours at room temperature with either (i) standard amounts of purified GSTA and GSTP in ELISA buffer (consisting of $10 \%$ normal human plasma heat treated at $60^{\circ} \mathrm{C}$ for one hour; $20 \mathrm{mM}$ EDTA; PBS; 0.05\% Tween 20), (ii) test cytosol diluted in ELISA buffer, or (iii) control cytosol with a known content of GSTA or GSTP. After washing three times, the plates were incubated for three hours with a polyclonal rabbit antihuman GSTA or GSTP antibody (prepared at the Department of Gastroenterology, University Hospital St Radboud, Nijmegen, the Netherlands) diluted in PBSTween containing 1\% bovine serum albumin (for anti-GSTA) or in PBS-Tween 10\% normal human plasma (for anti-GSTP). The plates were then washed again three times and incubated for two hours at room temperature with swine antirabbit IgG antibody conjugated with peroxidase, diluted 2000-fold with PBS containing $1 \%$ bovine serum albumin. After washing five times, the peroxidase substrate ortho-phenylenediamine in phosphate citrate buffer ( $0.1 \mathrm{M}$ citrate, $0.2 \mathrm{M} \mathrm{Na}_{2} \mathrm{HPO}_{4}, \mathrm{pH} 5.0$ ) with $0.01 \% \mathrm{H}_{2} \mathrm{O}_{2}$ was added and the plates were incubated at room temperature for 15 minutes. The resulting colour reaction was stopped by adding $100 \mu \mathrm{l}$ of $4 \mathrm{M} \mathrm{H}_{2} \mathrm{SO}_{4}$ to each well. Optical density was estimated at $492 \mathrm{~nm}$ with background subtraction at $620 \mathrm{~nm}$. The detection limits for GSTA and GSTP were 0.04 and $0.2 \mathrm{ng} / \mathrm{ml}$, respectively. All calibration curves and samples were measured in duplicate. Concentrations were calculated using a four parameter weighted logistic regression model with special software developed at 

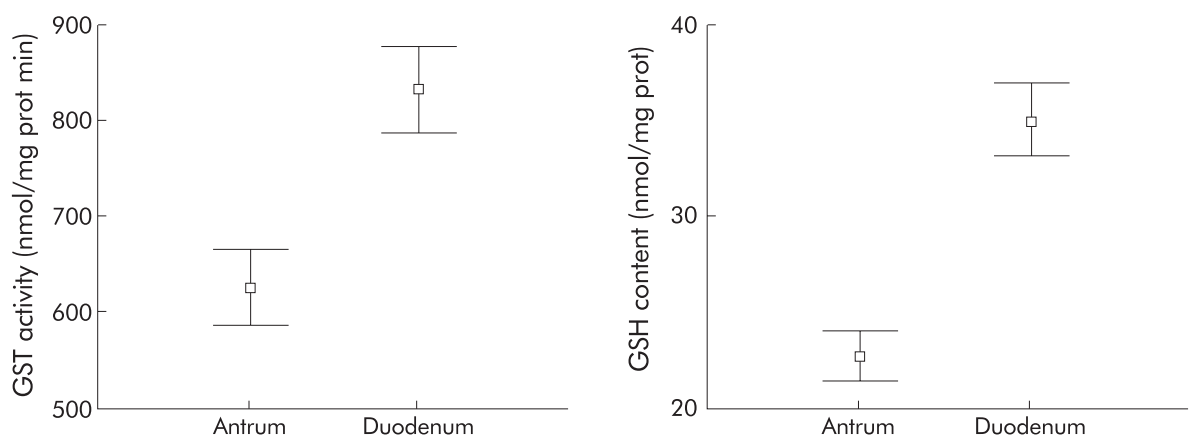

Figure 1 Antral and duodenal glutathione S-transferase (GST) activity and glutathione (GSH) content. Antral and duodenal GST activities were $626.5(9.3)$ and $832.0(22.2) \mathrm{nmol} / \mathrm{mg}$ protein $\mathrm{min}$, respectively $(\mathrm{p}<0.001)$. Antral and duodenal GSH content were $23.0(0.7)$ and $35.1(1.0) \mathrm{nmol} / \mathrm{mg}$ protein, respectively $(\mathrm{p}<0.001)$.
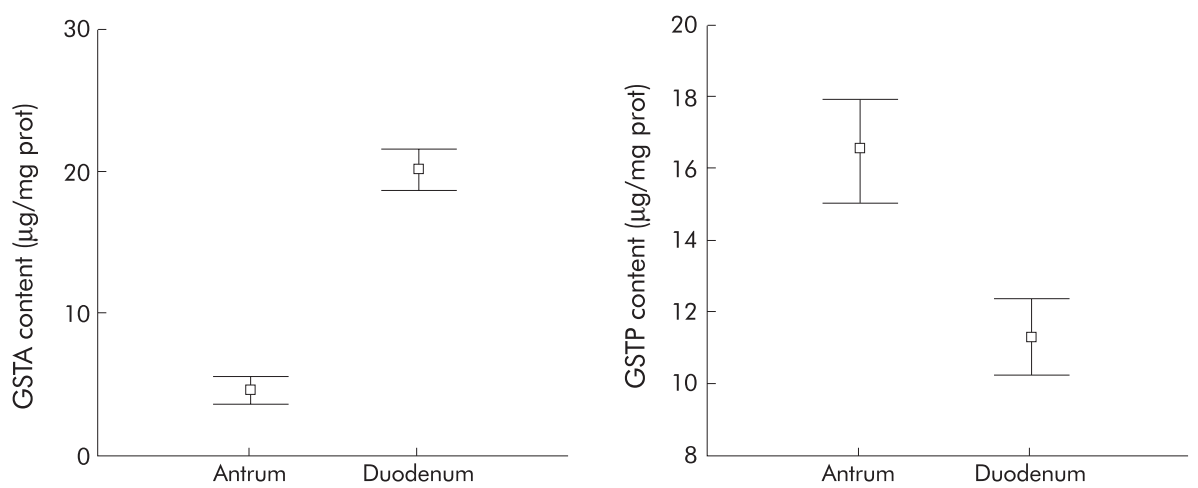

Figure 2 Antral and duodenal glutathione S-transferase alpha (GSTA) and pi (GSTP) content. Antral and duodenal GSTA content were 4.5 $(0.5)$ and $20.0(0.7) \mathrm{\mu g} / \mathrm{mg}$ protein, respectively $(\mathrm{p}<0.001)$. Antral and duodenal GSTP content were $16.5(0.7)$ and $11.2(0.5) \mu \mathrm{g} / \mathrm{mg}$ protein, respectively $(p<0.001)$

the Department of Gastroenterology, University Hospital St Radboud, Nijmegen, the Netherlands.

GSTT1 and GSTT2 levels were determined by western blot analyses, as described by de Bruin and colleagues. ${ }^{34}$

\section{Statistical analysis}

GST activity was calculated as $\mathrm{nmol} / \mathrm{min} / \mathrm{mg}$ total cytosolic protein, GSH content as $\mathrm{nmol} / \mathrm{mg}$ protein, and the contents of GSTA, GSTP, and GSTT as $\mu \mathrm{g} / \mathrm{mg}$ protein. All data are expressed as mean (SEM). The Mann-Whitney U test and the Wilcoxon signed rank test were used to assess differences between continuous variables, with $\mathrm{p}<0.05$ (two tailed) considered significant. Correlations were calculated using the Pearson correlation test. The Komolgorov-Smirnov test was used to assess the normal distribution of the estimated parameters. The distribution of the clinical variables between females and males was examined using the $\chi^{2}$ test. Categorical variables and tercentils of continuous variables were also compared by $\chi^{2}$ testing. Clinical variables were independent factors and GSH parameters were dependent determinants. For multivariate analyses of the effects of the qualitative clinical variables on the GSH parameters, ANOVA with adjustment for sex and endoscopic pathology was used. The SPSS statistical package (SPSS 7.0 for Windows 95) was applied for all statistical analyses.

\section{RESULTS}

Amounts of GSH, GSTA, and GSTP, as well as values for GST activity in the antral and duodenal mucosa are shown in figs 1 and 2. When the data were plotted as frequency histograms, we found that these parameters were normally distributed (data not shown). Total GSH content, GSTA content, and GST activity were significantly lower $(\mathrm{p}<0.001)$ in the antrum than in the duodenum. In contrast, GSTP content was significantly higher in antral compared with duodenal biopsies $(p<0.001)$. The ratio GSTP/GSTA was $23.6(4.9)$ in the antrum compared with only $0.9(0.1)$ in the duodenum. In antral biopsies, GST activity was significantly correlated with antral GSTP content $(r=0.3 ; \mathrm{p}<0.001)$ as well as with antral GSTA values $(r=0.2 ; \mathrm{p}<0.01)$ but not with GSH content. In the duodenum, GST activity was significantly correlated with duodenal GSTA content and antral GSH content (both $r=0.4$; $\mathrm{p}<0.001)$.

In eight of the 202 patients, we were also able to determine the same parameters of the glutathione system in the mucosa of the transverse and sigmoid colon. A similar distribution pattern was found for GSH content, GST enzyme activity, and levels of GSTA isoenzymes: duodenum > antrum > sigmoid colon >transverse colon (data not shown). In contrast, expression of GSTP isoenzymes was highest in the antrum and decreased in the proximal to distal direction. In earlier studies involving smaller groups of patients, a similar distribution for the GST enzyme activity pattern was described. ${ }^{4} 1019333536$

Marked sex related differences were observed with respect to antral GSH content and GST activity: values in females were significantly higher (both $\mathrm{p}<0.01$ ) than in males (table 2 ). Using the multivariate ANOVA method to test the impact of the clinical variables shown in table 1 , we found that sex was an independent variable with significant influence on antral GSH and GST. To validate these results, possible sex differences were also examined among endoscopically matched groups $(\mathrm{n}=166 ; 83$ males, 83 females). Antral GSH content was significantly higher in females compared with males (25.0 (1.1) v $21.6(0.9) \mathrm{nmol} / \mathrm{mg}$ protein; $\mathrm{p}<0.01)$ as was antral GST activity $(688(35) \vee 563(23) \mathrm{nmol} / \mathrm{min} / \mathrm{mg}$ protein; $\mathrm{p}<0.01)$. In addition, the difference in antral GST activity between 
Table 2 Sex related differences in the human mucosal glutathione (GSH) system in the antrum and duodenum $†$

\begin{tabular}{|c|c|c|}
\hline GSH parameter & $\begin{array}{l}\text { Males } \\
(n=104)\end{array}$ & $\begin{array}{l}\text { Females } \\
(n=98)\end{array}$ \\
\hline \multicolumn{3}{|c|}{ GSH content (nmol/mg protein) } \\
\hline Antrum & $21.2(0.8)$ & $24.8(1.0)^{* *}$ \\
\hline Duodenum & $34.2(1.4)$ & $36.2(1.2)$ \\
\hline \multicolumn{3}{|c|}{ GST activity ( $\mathrm{nmol} / \mathrm{min} / \mathrm{mg}$ protein) } \\
\hline Antrum & $576(21)$ & $679(32)^{* *}$ \\
\hline Duodenum & $813(30)$ & $851(33)$ \\
\hline \multicolumn{3}{|c|}{ GSTA content ( $\mathrm{\mu g} / \mathrm{mg}$ protein) } \\
\hline Antrum & $4.2(0.5)$ & $4.8(0.7)$ \\
\hline Duodenum & $20.4(1.0)$ & $19.5(1.0)$ \\
\hline \multicolumn{3}{|c|}{ GSTP content ( $\mu \mathrm{g} / \mathrm{mg}$ protein) } \\
\hline Antrum & $15.3(0.9)$ & $17.7(1.1)$ \\
\hline Duodenum & $11.3(0.7)$ & $11.1(0.7)$ \\
\hline
\end{tabular}

Values are mean (SEM)

†Matched for endoscopic diagnosis.

* * Significantly different from antral value in males, $p<0.01$

GST, glutathione S-transferase; GSTA, glutathione S-transferase alpha; GSTP, glutathione S-transferase pi.

Table 3 Sex related differences in glutathione S-transferase thetal (GSTT1) and theta2 (GSTT2) in the human mucosal GSH system

\begin{tabular}{|c|c|c|}
\hline & Males & Females \\
\hline \multicolumn{3}{|c|}{ GSTTl content ( $\mu \mathrm{g} / \mathrm{mg}$ protein) } \\
\hline Antrum & $\begin{array}{l}37.2(3.1) \\
(n=61)\end{array}$ & $\begin{array}{l}44.0(3.1) \\
(n=51)\end{array}$ \\
\hline Duodenum & $\begin{array}{l}37.6(3.0) \\
(n=57)\end{array}$ & $\begin{array}{l}42.4(3.1) \\
(n=50)\end{array}$ \\
\hline \multicolumn{3}{|c|}{ GSTT 2 content ( $\mu \mathrm{g} / \mathrm{mg}$ protein) } \\
\hline Antrum & $\begin{array}{c}8.9(1.1) \\
(n=49)\end{array}$ & $\begin{array}{l}11.7(1.8) \\
(n=52)\end{array}$ \\
\hline Duodenum & $\begin{array}{c}8.1(8.1) \\
(n=46)\end{array}$ & $\begin{array}{l}9.9(1.5) \\
(\mathrm{n}=52)\end{array}$ \\
\hline
\end{tabular}

Values are mean (SEM)

No significant differences were found between males and females or between the antrum and duodenum.

males and premenopausal females $(\mathrm{n}=18 ; 783$ (93) nmol/ $\mathrm{min} / \mathrm{mg}$ protein; $\mathrm{p}=0.01$ ) was greater when levels in males were compared with those in postmenopausal females $(n=80$; 658 (33) $\mathrm{nmol} / \mathrm{min} / \mathrm{mg}$ protein; $\mathrm{p}<0.05)$.

However, there were no differences in antral or duodenal content of GSTA, GSTP, GSTT1, or GSTT2 between males and females. The prevalence of gastrointestinal lesions and ulcers as well as intake of non-steroidal anti-inflammatory drugs (NSAID) was not statistically different between males and females. Although there was a significant age difference $(\mathrm{p}<0.01)$ between the sexes (males 57.5 (1.9) years; females 65.9 (1.8) years), no influence of age on the components of the upper gastrointestinal mucosal glutathione system was found by correlation analysis and scatter plots. Pathological endoscopic findings (ulcers, erosions, inflammatory changes) were found to be associated with significantly elevated GSH concentrations in the duodenal mucosa ( $p=0.008$ by ANOVA). No other GSH parameters were found to be influenced by endoscopic pathology.

As shown in table 3, the highest mucosal GST level was observed for GSTTI but this enzyme species was not affected greatly by sex or localisation. Mucosal GSTT1 level was about four times higher than GSTT2 (4l $v 10 \mu \mathrm{g} / \mathrm{mg}$ protein).

\section{DISCUSSION}

Cellular GSH and related enzymes such as GST and glutathione peroxidases are among the principal protective mechanisms against endogenous and exogenous toxic substances and free radical mediated damage in gastric and intestinal mucosa as well as in other tissues. GSH homeostasis at the cellular level is maintained by the balance between biosynthesis, uptake, oxidation, reduction, and export. In the present study, GSH content, GST enzyme activity, and levels of the GST classes alpha, pi, and theta in the antral and duodenal mucosa were investigated in patients undergoing upper gastrointestinal endoscopy for various clinical reasons. Intracellular GSH concentration was found to be quite low compared with the high enzymatic GST activity $\left(\mathrm{V}_{\max }\right)$ measured in vitro. However, the GSH level in vivo is sufficient for various GSH dependent enzymes and is well maintained by rapid resynthesis (GSSG reductase and GSH synthetase) as well as by GSH uptake into enterocytes from the luminal and vascular site.

Significant differences in the distribution of the parameters of the glutathione system in the mucosa of the antrum and duodenum were found. GSH content, GST activity, and GSTA content were lower and GSTP content higher in the antrum compared with the duodenum.

The duodenum and jejunum are the main sites of absorption of xenobiotics and nutrients while the stomach shows little absorptive activity. Therefore, the increased capacity of the GSH system in the duodenum may serve to protect duodenal tissue from toxic compounds. Alternatively, natural nutritional inducers (for example, flavonoids, indols, allyl sulphides) may enhance the activity of the intestinal GSH system to build up a protective barrier against noxious agents such as carcinogens and electrophilic drugs. ${ }^{37}$ Previously, we demonstrated an inverse correlation between tumour incidence and GST activity by plotting the estimated epithelial GST enzyme activity in different loci of the human gastrointestinal tract against the tumour incidence at different sites. ${ }^{11}$ A low GST content may therefore be a relevant factor in increased tumour risk.

In line with several previous studies on intestinal mucosa, ${ }^{4638}$ we did not find any influence of age on the GSH system in the mucosa of the upper gastrointestinal tract using correlation analysis and plotting scattergrams. However, other investigations $\mathrm{s}^{39}$ have provided evidence for diminution of GSH content and GST activity in gastric mucosa with increasing age. It has been speculated that this could contribute to age related carcinogenesis as the detoxification potential of colonic epithelial cells decreases in parallel with GST activity. ${ }^{12}$ Others have also shown that GST activity in the liver of elderly persons is $84 \%$ of that in younger subjects. ${ }^{4}$ It is possible that the lifespan of the enterocyte (3-4 days) is too short for expression of age effects.

In our study, a significant difference in antral GSH content and GST activity between males and females was found, with higher values detected in females (see table 2). Interestingly, the sex difference was restricted to the stomach mucosa and no difference was found in the duodenum. The higher GST activity of the antral mucosa in females could be due to enhanced expression of antral GSTT1 in females which however did not reach statistical significance $(p=0.068)$ for data matched for endoscopic diagnosis $(p=0.032$ for unmatched samples). Previously, we reported significantly higher levels of GSTA in the livers of females versus males. ${ }^{32}$ It is also known that the phase I cytochrome P450 detoxification enzymes show sex related differences in their expression. Higher P450 monooxygenase activity has been reported in the jejunal mucosa of males than in females. ${ }^{41}$ Singhal et al demonstrated sex differences in 10 patients with respect to expression of GSTs in the colon and skin. ${ }^{42}$ They found a 1.6-fold higher activity of colon GST in females compared with males. GSTP isolated from both sexes also differed in the stability and kinetics of inhibition. ${ }^{40}$ Temellini et al, studying 68 patients with respect to renal cortex and lung tissue, also found higher activity of GSTs in females than in males. ${ }^{4}$ However, the data 
Table 4 Influences of drugs and diet on the gastrointestinal glutathione (GSH) system (significant $p$ values)

\begin{tabular}{|c|c|c|c|c|c|c|c|c|c|}
\hline \multirow[b]{2}{*}{ Drug } & \multicolumn{3}{|c|}{$\begin{array}{l}\text { GST } \\
\text { activity }\end{array}$} & \multicolumn{2}{|l|}{ GSTA } & \multicolumn{2}{|l|}{ GSTP } & \multicolumn{2}{|l|}{ GSTTI } \\
\hline & $\mathrm{n}$ & A & D & A & D & A & D & A & D \\
\hline NSAID & 31 & - & - & - & - & - & - & - & 0.020 \\
\hline Cortisol & 15 & - & - & - & & 0.007 & 0.007 & - & - \\
\hline Cytostatic & 7 & 0.015 & - & - & - & - & - & - & - \\
\hline Analgesic & 14 & - & - & - & - & - & 0.037 & 0.011 & - \\
\hline Heparin & 83 & - & - & - & - & 0.027 & - & 0.022 & - \\
\hline Insulin & 15 & - & - & 0.019 & - & - & - & 0.003 & - \\
\hline Diuretics & 59 & 0.012 & - & - & - & 0.035 & 0.020 & - & - \\
\hline ACE inhibitors & 35 & - & - & - & - & - & 0.018 & - & - \\
\hline Cisapride & 8 & 0.036 & 0.040 & 0.012 & - & - & - & - & - \\
\hline Ranitidin & 20 & - & - & - & - & - & - & 0.023 & - \\
\hline High fruit intake & 143 & - & - & - & - & - & - & 0.005 & \\
\hline High vegetable intake & 153 & - & - & - & 0.038 & - & 0.037 & - & - \\
\hline
\end{tabular}

GST, glutathione S-transferase; GSTA, glutathione S-transferase alpha; GSTP, glutathione S-transferase pi ; GSTT 1, glutathione S-transferase theta l; $A$, antrum; $D$, duodenum; $n$, number of patients on specific drug compared with all not on drugs $(n=25)$ by multivariate ANOVA.

Cytostatic drugs suppressed GST activity while the other drugs or diets had an inducing effect No significant effects were observed for aspirin, antibiotics, nitrates, $\beta$ blockers, proton pump inhibitors, digitalis, thiamazol, calcium antagonists, L-thyroxin, and high intake of garlic and onions.

Patients on high vegetable and high fruit intake (4-7 days a week) were compared with those on low intake ( $1-3$ days a week) ( $n=42$ for low vegetable and $n=49$ for low fruit consumption)

in the literature are inconsistent. Loguercio et al did not find any differences in the activity of GSTs in gastric mucosa between males and females. ${ }^{39}{ }^{40}$ In the colonic mucosa, Szarka et al found no association of GST parameters with patient sex. ${ }^{36}$ However, the number of investigated patients in the above cited studies was considerably lower than in the present study. Numerous studies in rodents have shown that GSTs are subject to sex specific or ontogenetic variations. ${ }^{1}$ When examining the influence of the menopause, the difference in antral GST activity was greater between males and females before the menopause compared with after the menopause.

Limited studies have indicated a role for thyroxin, pituitary growth hormone, and testosterone in sex dependent expression of GST isoenzymes by pretranslational mechanisms in adult rat liver. ${ }^{122} 43$ Lavoie and Chessex described higher intracellular total GSH content in human neonatal tissues from females compared with males. ${ }^{44}$ Taking into consideration that the glutathione system is a central mechanism in the defence against toxic free radicals and carcinogens, it may be hypothesised that specific tissues in females are potentially better protected than those in males. However, it is also possible that there is enhanced oxidant stress in the antral stomach mucosa of females and the increased GSH system capacity indicates an adaptive and compensatory response of this tissue.

Animal studies have shown that drugs can profoundly affect the intestinal GSH system ${ }^{30}$ but studies in humans with clinically relevant drugs have not yet been published. Most animal studies indicated an inducing effect of dietary exogenous compounds on intestinal GST activity. ${ }^{30}$ The mucosal GSH concentration itself is barely inducible. We found that important drugs such as insulin, heparin, and cortisol derivatives enhance predominantly GSTP and less markedly GSTA and GSTT1 levels (table 4). Much less effective in this regard are analgesic (paracetamol, metamizol) and diuretic drugs. In a unique way, cisapride treatment is associated with higher activities of the GST in the antrum and duodenum while cytostatic drugs seem to depress this enzyme. The majority of the observed drug effects may be unspecific but some may indicate enhanced detoxification capacity (cisapride) and decreased tissue resistance (cytostatics) of the gastrointestinal mucosa. NSAIDs had no appreciable gross effect on the mucosal GSH system but time and dose dependent effects were observed. Initial depression of mucosal GSH content was dose dependent and could be explained by tissue depletion of GSH due to a drug specific effect followed by restoration and adaptation over time (data not shown). NSAIDs only affected the antral but not the duodenal mucosa.

Vegetable consumption is known to induce the GST enzyme system both in human ${ }^{16}$ and animal studies. ${ }^{30}$ While high fruit intake seems to enhance only the GSTT1 level of the antral mucosa, vegetable diets lead to higher duodenal GSTA and GSTP levels. Comparison of high and low consumption of potatoes, onions, garlic, spices, rice, and bread did not reveal significant differences in GSH and its enzymes. Epidemiological data demonstrate that vegetables protect us from neoplasia of the colon. ${ }^{45}$ Therefore, our data may indicate that induction of intestinal GST is beneficial and could be used as a marker of cytoprotection. ${ }^{46}$ While GSTA and GSTP expression are related to specific exogenous factors and constitute a response of the differentiated mature function of the enterocytes of the mucosa, GSTT1 and GSTT2 levels are not influenced by sex or localisation. Most likely, GST class theta enzymes play a role as precursors of the specified functionally committed enzyme species.

In conclusion, the GSH system of the upper gastrointestinal tract most likely serves as an antitoxic barrier for the mucosa thus preventing the noxious effects of dietary toxins at their portal of entry. Increased expression of GST enzymes by higher intake of vegetables and fruits could be beneficial and may lead to chemoprotection of the gut mucosa.

\section{ACKNOWLEDGEMENTS}

This work was partially supported by a grant from Braun Melsungen Foundation.

\section{Authors' affiliations}

H Hoensch, Department of Gastroenterology, General Hospital of Gross-Gerau, Gross-Gerau, Germany

I Morgenstern, G Petereit, M Siepmann, W Kirch, Institute of Clinical Pharmacology, Technical University Dresden, Dresden, Germany W H M Peters, H M J Roelofs, Department of Gastroenterology, University Hospital St Radboud, Nijmegen, the Netherlands

\section{REFERENCES}

1 Hayes JD, Pulford DJ. The glutathione S-transferase supergene family: regulation of GST and the contribution of the isoenzymes to cancer chemoprotection and drug resistance. Crit Rev Biochem Mol Biol 1995;30:445-600. 
2 Hayes JD, Strange RC. Glutathione S-transferase polymorphism and their biological consequences. Pharmacology 2000;6: 154-66.

3 Cholerton S, Daly AK, Idle JR. The role of individual human cytochromes P450 in drug metabolism and clinical response. Trends Pharmacol Sci 1992;13:434-9.

4 Temellini A, Castiglioni M, Giuliani L, et al. Glutathione conjugation with 1-chloro-2,4-dinitrobenzene (CDNB): interindividual variability in human liver, lung, kidney and intestine. Int J Clin Pharmacol Ther $1995 ; 33: 498-503$

5 Mannervik B, Danielson UH. Glutathione transferase structure and catalytic activity. Crit Rev Biochem 1988;23:283-337.

6 Kamisaka K, Habig WH, Ketley JN, et al. Multiple forms of human glutathione S-transferase and their affinity for bilirubin. Eur J Biochem 1975;60:153-61.

7 Meyer DJ, Coles B, Pemble SE, et al. Theta a new class of glutathione S-transferases purified from rat and man. Biochem J 1991;274:409-14

8 Meikle I, Hayes JD, Walker SW. Expression of an abundant alpha-class glutathione S-transferase in bovine and human adrenal cortex tissues. $J$ Endocrinol 1992;132:83-92.

9 Tateoka N, Tsuchida S, Soma Y, et al. Purification and characterization of glutathione S-transferases in human kidney. Clin Chim Acta 1987; 166:207-18.

10 Peters WHM, Wormskamp NGM, Thies E. Expression of glutathione S-transferases in normal gastric mucosa and gastric tumours. Carcinogenesis 1990:11:1593-6.

11 Peters WHM, Roelofs HM, Hectors MPC, et al. Glutathione and glutathione S-transferases in Barrett's epithelium. Br J Cancer 1993;67: 1413-17

12 Peters WHM, Roelof HM, Nagengast FM, et al. Human intestinal glutathione S-transferases. Biochem J 1989;257:471-6.

13 Awasthi YC, Sharma R, Singhal SS. Human glutathione S-transferases. Int J Biochem 1994;26:295-308

14 Warholm M, Guthenberg C, Mannervik B. Molecular and catalytic properties of glutathione transferase mu from human liver. An enzyme efficiently conjugating epoxides. Biochemistry 1983;22:3610-17.

15 Campbell E, Takahashi Y, Abramovitz M, et al.. A distinct human testis and brain mu-class glutathione S-transferase: Molecular cloning and characterization of a form present even in individuals lacking hepatic type mu isoenzymes. J Biol Chem 1990;265:9188-93.

16 Nijhoff WA, Grubben MAL, Nagengast FM. Effects of consumption of brussels sprouts on intestinal and lymphocytic glutathione S-transferases in humans. Carcinogenesis 1995;16:2125-8.

17 Di llio C, Aceto G, Del Boccio E, et al. Purification and characterization of five forms of glutathione transferase from human uterus. Eur J Biochem 1988;171:491-8.

18 Hussey AJ, Hayes JD, Beckett GJ. The polymorphic expression of the neutral glutathione S-transferase in human mononuclear leucocytes as measured by specific radioimmunoassays. Biochem Pharmacol 1987:36:4013-15.

19 Peters WHM, Boon CEW, Roelofs HM, et al. Expression of drug-metabolizing enzymes and P-170 glycoprotein in colorectal carcinoma and normal mucosa. Gastroenterology 1992;103:448-55.

20 Schipper DL, Verspaget HW, Mulder TPJ, et al. Correlation of glutathione S-transferases with overall survival in patients with gastric carcinoma. Int J Oncol 1996:9:357-63.

21 Tsuchida S, Sato K. Glutathione transferases and cancer. Crit Rev Biochem Mol Biol 1992;27:337-84

22 Howie AF, Forrester LM, Glancey M, et al. Glutathione S-transferase and glutathione peroxidase expression in normal and tumour human tissues. Carcinogenesis 1990;11:451-8.

23 Moorghen M, Cairns J, Forrester LM, et al. Enhanced expression of glutathione S-transferases in colorectal carcinoma compared to non-neoplastic mucosa. Carcinogenesis 1991;12:13-17.
24 Lewis A, Forrester LM, Hayes JD. Glutathione S-transferase isoenzymes in human tumours and tumour derived cell lines. $\mathrm{Br} J$ Cancer 1989;60:327-32.

25 Peters WHM, Roelofs HM. Biochemical characterization of resistance to mitoxantrone and adriamycin in Caco-2 human colon adenocarcinoma cells: A possible role for glutathione S-transferases. Cancer Res 1992:52:1886-90.

26 Mulder TPJ, Roelofs HM, Peters WHM, et al Glutathione S-transferases in liver metastases of colorectal cancer. A comparison with normal liver and primary carcinomas. Carcinogenesis 1994;15:2149-53.

27 Lowry OH, Rosebrough NJ, Farr AL, et al. Protein measurement with the folin phenol reagent. J Biol Chem 1951;193:265-75.

28 Habig WH, Pabst M, Jakoby WB. Glutathione-S-transferases. The first enzymatic step in mercapturic acid formation. J Biol Chem enzymatic step in merc

29 Fahey RC, Newton GL. Determination of low-molecular-weight thiols using monobromobimane fluorescent labeling and high-performance chromatography. Methods Enzymol 1987;143:85-96.

30 Niihoff WA, Groen GM, Peters WHM. Induction of rat hepatic and intestinal glutathione S-transferases and glutathione by dietary naturally occurring anticarcinogens. Int J Oncol 1993;3:1131-9.

31 Mulder TPJ, Peters WHM, Wobbes T, et al. Measurement of glutathione S-transferase P1-1 in plasma. Cancer 1997;80:873-80.

32 Mulder TPJ, Court DA, Peters WHM. Variability of the glutathione S-transferase $\alpha$ in human liver and plasma. Clin Chem 1999:45:355-9

33 Peters WHM, Nagengast FM, Wobbes T. Glutathione S-transferases in normal and cancerous human colon tissue. Carcinogenesis 1989:10:2371-4.

34 de Bruin WCC, Wagenmans MM, Board PG, et al. Expression of glutathion S-transferase $\theta$ class isoenzymes in human colorectal and gastric cancers. Carcinogenesis 1999;20:1453-7.

35 Peters WHM, Kock L, Nagengast FM, et al. Biotransformation enzymes in human intestine: critical low levels in the colon? Gut 1991;32:408-12.

36 Szarka CE, Pfeiffer GR, Hum ST, et al. Glutathione S-transferase activity and glutathione S-transferase mu expression in subjects with risk for colorectal cancer. Cancer Res 1995;55:2789-93.

37 Hoensch HP, Steinhardt HJ, Weiss H, et al. Effects of semisynthetic diets on xenobiotic metabolizing enzyme activity and on morphology of small intestinal mucosa in humans. Gastroenterology 1984;86:1519-30

38 Tsuchida S, Sekine Y, Shineha R, et al. Evaluation of placental glutathione S-transferase form (GST pi) in tumour tissues and the levels in sera of patients with cancer. Cancer Res 1989:49:5255-9.

39 Loguercio C, Taranto D, Vitale LM, et al. Effect of liver cirrhosis and age on the glutathione concentration in the plasma, erythrocytes and gastric mucosa of man. Free Radic Biol Med 1996;20:483-8.

40 Loguercio $C$, Taranto D, Beneduce $F$, et al. Age affects glutathione content and glutathione-transferase activity in human gastric mucosa. Ital J Gastroenterol 1996:28:477-81.

41 Sundseth SS, Alberta JA, Waxman DJ. Sex-specific, growth hormone regulated transcription of the cytochrome $\mathrm{P} 4502 \mathrm{C} 11$ and $2 \mathrm{C} 12$ genes. $J$ Biol Chem 1992;267:3907-14

42 Singhal SS, Saxena M, Awasthi S, et al. Gender-related differences in the expression and characteristics of glutathione S-transferases of human colon. Biochim Biophys Acta 1992;1171:19-26.

43 Srivastava PK, Waxman DJ. Sex dependent expression and growth hormone regulation of class alpha and class mu glutathione S-transferase mRNAs in adult rat liver. Biochem J 1993;294:159-65.

44 Lavoie JC, Chessex P. Gender and maturation affect glutathione status in human neonatal tissues. Free Radic Biol Med 1997;23:648-57.

45 Witte JS. Relation of vegetable, fruit and grain consumption to colorectal adenomatous polyps. Am J Epidemiol 1996, 144:1015-27.

46 Hoensch HP, Hartmann F. The intestinal enzymatic biotransformation system: potential role in protection from colon cancer. Hepatogastroenterology 1981;28:221-8. 